\title{
Effect of doodling on Iranian EFL learners' foreign language classroom anxiety and lexical retrieval
}

\author{
Roohani, Ali $\bowtie$ \\ Shahrekord University, Iran (roohani.ali@gmail.com) \\ Naseri, Farshad \\ Shahrekord University, Iran (fnshahrkord@gmail.com)
}

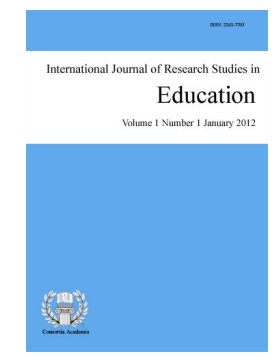

ISSN: 2243-7703 Online ISSN: 2243-7711

OPEN ACCESS

\section{Abstract}

Research on doodling as a psychological mechanism against boredom in learning contexts has produced mixed results. Whereas some studies accentuate its compensatory potential, some downgrade it, compared with other retention strategies. This study applied the doodling strategy in English as a foreign language (EFL) classroom, where the load of lexical input is high and EFL learners experience a high level of anxiety. It investigated the effect of doodling on Iranian EFL learners' lexical retrieval/retention and foreign language classroom anxiety. The participants comprised of 40 EFL learners in a high school in Iran. They were divided into a treatment and a control group. Their scores on an English placement test and the Foreign Language Classroom Anxiety Scale (FLCAS) were recorded as the pretests. Both groups were instructed on their daily English syllabus for 20 minutes nonstop to exceed the attention span, and then they were taught a list of 14 lexical items for 5 sessions, one session each week. The treatment group was provided with a space on their vocabulary sheets to do either structured or unstructured doodling. Then, both groups were assessed on immediate and delayed lexical posttests. The statistical analyses revealed that the doodlers' short-term memory retrieval of words improved in the experimental group more than the control group. However, no significant differences were observed between two groups regarding their long-term memory retrieval of words. Moreover, the FLCAS posttest results indicated no significant reducing effect on the learners' foreign language anxiety. Findings are discussed and implications are provided.

Keywords: doodling; EFL learners; foreign language anxiety; lexical retrieval; memory 


\section{Effect of doodling on Iranian EFL learners' foreign language classroom anxiety and lexical retrieval}

\section{Introduction}

Learning a new language in the atmosphere of explicit classroom instruction has been intertwined with a considerable amount of anxiety. This overwhelming sense of classroom anxiety impedes the natural progress of second/foreign (L2) learning, and it can sometimes derive a negative attitude towards any L2 learning attempt. Therefore, anxiety is regarded as one of the predictors of L2 learning (Dörnyei, 1994). Excessive level of anxiety, as a destructive ego-threatening facet, is repeatedly reported to have clashing relationships with identity, motivation, and self-satisfaction, which are important parameters in determining the success of L2 learners (Dörnyei, 1994; MacIntyre, 2002; Stroud \& Wee, 2006). Sparks and Ganschow (1991) believe that anxiety can influence L2 learning not as an independent cause, but as an epiphenomenon, which is a byproduct of low encoding capabilities. In actuality, deficient performance can result in debilitative anxiety and this, in turn, can disturb the subsequent encoding situations due to the interplay of affective and cognitive dimensions of human totality. As Tsui (1996) concludes, anxious learners preserve their self-esteem against humiliation and criticism by means of being reticent in the classroom, which decreases the chance of trial and error in the process of language learning.

Language classroom anxiety seems to exert more pressure on those skills and subskills which are mostly affiliated with memory, specifically vocabulary learning here. L2 learners, particularly adolescents and adults, deal with a giant world of information nowadays. This huge load of unstructured information usually involves a lot of processing in the brain and restricts the short-term memory's proper functioning. As a result, anxiety exercises more pressure, hand in hand with limited short-term memory performance, on the lexical learning skills. MacIntyre and Gardner's (1989) study shows that lexical retention of highly anxious learners significantly differs from that of less anxious learners, and even the learning process of the lexical items take place at a slower pace. This means that communicative anxiety acts as a filter and undoes previous lexical gains.

In this vein, some attempts have been made to reduce foreign language anxiety in order to optimize L2 learning in classroom settings. One of the strategies, which may look at the first glance too infantile, is doodling. This psychologically unloading safety valve is proposed as an unconscious mechanism through which learners can implicitly focus on the content, while discharging much of the details' pressure. In fact, when an individual gets bored or stressful, his receptive functioning reaches its performance peak, and his attentive focusing power starts declining, doodling can aid mind to concentrate more (Andrade, 2010). As cognitive processing is at work when L2 learners learn a list of new words, doodling, as a covertly meaningful activity, can let the stress and irrelevant feelings out, and leave more space in the memory to pick up more lexical items.

The present study aimed at looking into the effect of applying doodling activity/ technique to the context of L2 learning to investigate its potentials in boosting the lexical short- and long-term memory uptake, that is, short- and long-term memory retrieval of words, as well as its effect on reducing the foreign language anxiety in the class. Lexical learning often imposes some pressure on L2 learners' minds due to the fact that it involves multiple processing of information dealing with denotative, connotative, and idiomatic aspects of lexicon. This pressure might be intensified by the anxiety due to the inherent nature of a foreign language classroom. Therefore, it is important to look for techniques to offset this pressure in L2 lexical learning. This study with its focus on doodling activity is a step in that direction.

\section{Background of the study}

Anxiety - The concept of anxiety has long been recognized as a decelerating factor in any type of learning. It 
relates to feelings like "uneasiness, frustration, self-doubt, apprehension, or worry" (Scovel, 1978, p. 134). Psycho-physiologically, it is defined as "an organic response, characterized by apprehension and increased surveillance in situations of uncertain danger or potential threats to the integrity of the organism" (Grillon, 2008, as cited in Leal, Goes, da Silva, Teixeira-Silva, 2017, p. 148). Unlike such a negatively held perspective regarding anxiety, research findings split the anxiety into two opposing sides. Kleinmann (1977) contrasts facilitating anxiety with debilitative anxiety in that the former can influence some aspects of L2 learning positively. However, the general impression, which is taken by most teachers and learners on anxiety, depicts it as mostly detrimental to L2 learning.

Anxiety can take on different forms. Trait anxiety refers to an individual's personality characteristic which reflects anxiety externally. State anxiety, occurs at a particular point of time due to a momentary occurrence. Situational anxiety, as a third type of anxiety, deals with a specific situation in which an individual almost stably gets anxious. Foreign language classroom anxiety (FLCA) falls within the third type of anxiety. It means that the context of foreign language classroom perpetuates a sense of worry resulting in a mental block that hinders easy uptake.

Despite the view that language anxiety seems competence-based, Stroud and Wee (2006) postulate that anxiety is primarily entangled with identity-threatening factors, "where an individual may be more concerned with maintaining his or her relationship with particular groups than with his or her language abilities" (p. 300). Following this view, before enquiry for external causes of anxiety, L2 researchers need to look for those features of language learning context which create friction between L2 learning and identity. Some studies have showed that others' perception of an individual can have negative impacts on the individual's performance in spite of his acceptable competence (Allwright \& Bailey, 1991). Also, cultural differences can be the source of anxiety. Lim (2004) found out that Asian learners manifested higher levels of anxiety, compared with their European and North American counterparts. As another meta-competence factor, motivation plays a quintessential role in downgrading or upgrading the effect of anxiety on L2 learners' learning. Essentially, motivation can be assumed, in most cases, as the real counteraction of anxiety, with which it negatively correlates. Studies have also showed that there is a kind of interplay between anxiety and motivation, and motivation can be regarded as a determinant factor in relation to anxiety (Dörnyei, 2001; Randler, Wüst-Ackermann, Vollmer, \& Hummel, 2012). Moreover, some scholars (e.g., Tremblay \& Gardner, 1995) propose that anxiety is the antecedent to motivation, along with some other variables.

Acknowledging the competence-based factors influencing and causing anxiety-arousal, research has confirmed that poor linguistic performance can lead to higher levels of anxiety. For instance, insufficient skills in speaking ability can cause pressure and anxiety in L2 learners (Bila, 2005). Even the deficient skills in the first language (L1) can result in anxious state of mind when taking part in L2 classroom (Sparks, Ganschow, \& Javorsky, 2000). Also, Young's (1990) comprehensive taxonomy of foreign language anxiety includes teacher-learner interactions, classroom procedures, and language testing as competence-oriented factors which foment affective disorders. To sum up, foreign language anxiety in the class is an impediment that can prevent mental capacities from optimal functioning and affect cognitive processing power.

Doodling, anxiety, and lexical retrieval - Once deemed as a time-wasting idle scribbling, doodling gradually shifted away from a meaningless activity to a compensatory activity which would aim at keeping the mental awareness and the external world as close and entangled to each other as possible in order to diminish daydreaming and mind wandering. Basically, doodling does not let the mind shut down and keeps it at least minimally active and conscious. Traditionally, it is used to stimulate kids' drawing creativity and capacities; doodling may seem ineffective for mature and adolescent humans in some situations. Contrary to this view, Brown (2011) views doodling, rooted in Freud's psychology, as a way of psychoanalysis to dig out hidden personal features. It can aid psychologists and even individuals themselves to uncover personality characteristics and pinpoint emotions and relieve negative feelings. Among the negative feelings, anxiety is one of the most prevalent feelings which is experienced by L2 learners. Doherty (2005) states that doodling is an activity which 
can decrease the amount of stress in foreign language classroom experienced by L2 learners. The qualitative study conducted by Siagto-Wakat (2016) shows that doodling could be used as an anxiety-reducing activity for university students in an EFL context. The participants utilized doodling as a nonverbal tool to pour their anxiety into unconscious phases, as well as implicitly depicting their anxiety sources. The findings confirm that doodling can surface anxiety experience, and help teachers detect the root causes which hinder L2 uptake.

Brown (2011) points to the potentials of doodling for better concentration and recall. In fact, doodling is a preemptive measure to maintain concentration when mind is going to lose its concentration under the huge load of information density. Andrade's (2010) pioneering work was an attempt to feature this special function of doodling. Her participants were asked to listen to a monotonous and lengthy call which included a lot of names and detailed information. The treatment group had a chance to do structured doodling on a piece of paper while listening. The outcome of the study showed that doodling made treatment group recalls 29 percent more information. Also, the study by Singh and Kashyap (2015) revealed that the retrieval strategy of recognition, compared to recall strategy, benefited more from doodling. Moreover, to compare the effect of structured doodling with three other modules, namely non-doodling, unstructured doodling, and note-taking, Boggs, Cohen, and Marchand (2017) devised a similar task demanding participants to listen to a 5-minute audio and, then, answer a memory-based quiz. The results indicated that neither types of doodling had significant effect on the participants' recall ability compared to that of note-takers. Prior to the study by Boggs et al. (2017) study, Chan (2012) had investigated the effect of doodling on a visual recall task. The results, against the expectation, manifested that doodling could negatively influence visual recall. Meade, Wammes, and Fernandes (2019) confirmed the results of Chan's study and reported that doodling strategy, among the three memory-strengthening modalities, namely doodling, drawing, and writing, had the least retrieval advantage.

From the early days of L2 instruction, lexis has assumed an integral part in any language teaching courses. Nevertheless, due to the greater emphasis on structural accuracy, it has been in the shadow of grammatical considerations. Hopefully, recent research findings support the grammaticalized lexis approach, developed by Lewis (1993). In essence, Lewis claims that, in line with emergentists' views towards language learning, language acquisition revolves around lexis and the structural skeleton of human languages is shaped by single words or lexically unfragmented chunks that, subsequently, depict the structural patterns of language. In this view, vocabulary turns out to be one of the most elemental components of language. Most often, learning new lexical items in the atmosphere of foreign language class may raise a sense of anxiety. As Awan, Azher, Anwar, and Naz (2010) have pointed out, anxiety is a key obstacle for linguistic, especially lexical, retention in L2 classes. A remedy for sustaining memory in lexical uptake and retention may be doodling while L2 learners are fed up with listening in the class since this technique/activity may unload excessive cognitive and affective burdens and evacuate more space for new loads. Romani and Martin (1999), summarizing the research findings, highlight the role of short-term memory in the long-term memory retrieval of words and maintain that "the activation and maintenance of a particular code in short-term memory is necessary to carry out the processing that results in the long-term memory traces for those codes and their interconnections with prior knowledge" (p. 57). Doodling, in Andrade's (2010) study, is qualified as a short-term memory booster and, thus, can have positive effects on long-term memory.

Put all the above issues together, it is concluded that the results of the prior studies conducted on the efficacy of doodling cannot lead us to a unified conclusion, and context-specific variables may have a role in the final outcome about the efficacy of doodling technique. Perhaps, doodling works well when individuals are suffering from a boring auditory input and have no other choice to escape from that situation. The current study used doodling as a nonverbal activity in an EFL context with the hope to offset the negative effects of anxiety in L2 lexical learning. To the best of the current researcher's knowledge, almost no study has examined the effectiveness of doodling on L2 vocabulary learning. Research in the literature such as Andrade's (2010) study was related to the immediate effect of doodling on vocabulary recall rate. Thus, a gap is seen in the literature on the comparative effect of doodling on L2 lexical retrieval of words in terms of short- and long-term memory.

4 Consortia Academia Publishing (A partner of Network of Professional Researchers and Educators) 


\subsection{Research questions}

In the area of L2 pedagogy, the use of doodling as an alleviating mechanism or strategy has not received much attention, and there is little research on this variable, particularly in the realm of vocabulary learning. Little is known about the effect of doodling on the rate and quality of lexical uptake. Besides, the results of the prior studies conducted on the effectiveness of doodling activity/strategy with regard to memory retention of information are inconsistent. Therefore, investigating the effect of doodling on memory retrieval of words could contribute to the field. The results may help language teachers and learners understand to what extent they can utilize this technique to optimize L2 vocabulary learning. Moreover, it is claimed that doodling can act like psychotherapy (Gupta, 2016). Given the shortage of empirical research on doodling in foreign language teaching/learning contexts, it is equally important to examine whether this technique can be effective to significantly reduce anxiety in an EFL class which is often loaded with foreign language anxiety and stress. Therefore, the purpose of the present study was two-fold: to investigate the effect of doodling on L2 lexical retrieval of words in terms of short- and long-term memory and to look into the effects of doodling on the FLCA. Taken these into consideration, the following research questions were address in the current study:

$>\quad$ Does using doodling in an EFL classroom have any significant effect on short-term memory retrieval of target English words?

$>\quad$ Does doodling in an EFL classroom have any effect on long-term memory retrieval of target English words?

$>\quad$ Does doodling in an EFL classroom have any effect on reducing foreign language anxiety?

\section{Method}

\subsection{Participants}

A total of 40 Iranian EFL learners were targeted as the participant of the present study. Their average age was 17, and they were studying English at a state high school in Isfahan province of Iran. They had five years of English learning experience. They comprised of experimental and control groups, each with 20 EFL learners.

\subsection{Instruments and materials}

Oxford Placement Test (OPT) was used to measure the lexical knowledge of the participants. The OPT consisted of three sections, namely grammar and vocabulary, reading, and writing. Of the three parts, just the first part was administered to the participants, and their scores were used as a covariate in data analysis in the present study. Additionally, a list of 70 words, which were unknown to the EFL participants, was used. They were selected from a list of 100 new words from their high school English textbook. Each session, 14 of these words were presented and explained, along with short definitions and examples in the sentence context. To examine their sort-term memory vocabulary gains or retention/retrieval of words, 5 short tests (quizzes) on the newly taught lexical items were used after each session. Additionally, another vocabulary retention test was administered to the same participants after three weeks at the end of the instruction. This vocabulary test which asked the test takers to match the instructed vocabularies with their definitions was used as a delayed posttest to investigate the long-term memory retrieval of the instructed vocabulary, which was the focus of the second research question of the study.

The third research question dealt with foreign language anxiety in the class. The adapted version of the FLCAS, developed by Horwitz, Horwits, and Cope (1986), was selected as the anxiety measurement scale. Due to the cultural differences among various communities, the adapted version of the scale was used. It comprised of 21 five-point Likert scale items ( 1 = Strongly Disagree, $2=$ Disagree, $3=$ Neither Agree nor Disagree, $4=$ 
Roohani, A., \& Naseri, F.

Agree, 5 = Strongly Agree). The scale was administered to the participants prior to the study, as the pretest, and at the end of the instruction, as the posttest.

\subsection{Procedure}

After administering the OPT and FLCAS to control their lexical knowledge and level of foreign language anxiety prior to the instructions in the class, the participants in the two groups (experimental and control) received instruction every week. Smallwood and Schooler (2006) maintain that "when mind wandering occurs, the executive components of attention appear to shift away from the primary task, leading to failures in task performance and superficial representations of the external environment" (p. 946). Also, doodling occurs when the tendency for daydreaming starts in moments of boredom (Andrade, 2010). With this perspective, the daily classroom activities, including assessment and teaching new words and materials, where done to the point where the participants in both groups looked bored.

Dukette and Cornish (2009) have used the term sustained attention to refer to the consistent focus of the mind over a period of time on any mental activity. They claim that the amount of sustained attention does not exceed 20 minutes for teenagers and adults. Other studies (e.g., Benjamin, 2002; Goss-Lucas \& Bernstein, 2005) also show that the peak of attentional zone revolves around 15 minutes, and thereby, the concentration power starts to diminish, especially in passive and inactive situations. Therefore, at this point (20 minutes of teaching) when the participants looked to be disengaged from the active participation, both groups were provided with a list of 14 new lexical items tagged with explanation and an exemplar sentence. Additionally, the experimental group was given a blank space for unstructured doodling and a set of black-and-white sheets for those who preferred structured doodling. Unlike other studies that allowed for one type of doodling, either structured or unstructured, the experimental group was not restricted to just one of them in order to see the potential of doodling, on the whole. Then, the participants were given a short test (quiz) on the newly taught lexical items to look into the short-term memory gains and examine the doodling effect. The instruction lasted for five weeks (one session per week). Three weeks later, a delayed vocabulary retention posttest was administered to the same participants in the two groups to investigate the long-term memory effect of doodling on the retrieval of words. Meanwhile, they completed the FLCAS to reflect the effect of doodling on the reduction of anxiety levels in the EFL class. The data from the vocabulary quiz tests, delayed vocabulary test, and FLCAS were analyzed through inferential statistics to answer the research questions of the study.

\section{Results}

\subsection{Short-term memory retrieval of words}

To answer the first research question, an analysis of covariate (ANCOVA) was used. The scores on OPT on vocabulary part were used as a covariate to control for the learners' lexical knowledge. The mean score of all 5 vocabulary quizzes for each participant was used as the dependent variable in the data analysis. Table.1 shows the descriptive statistics for both short- and long-term memory retention of the target words in the experimental and control groups.

\section{Table 1}

Descriptive statistics for memory retrieval of the target words in the experimental and control groups

\begin{tabular}{llccccc}
\hline \multicolumn{1}{c}{ Group } & \multicolumn{1}{c}{ Test } & $\mathrm{N}$ & $M$ & $S D$ & Skewness & Kurtosis \\
\hline \multirow{2}{*}{ Experimental } & Short-Term & 20 & 5.54 & 1.31 & -.60 & -1.16 \\
& Long-Term & 20 & 2.40 & 2.83 & 1.68 & 2.60 \\
\hline \multirow{2}{*}{ Control } & Short-Term & 20 & 3.84 & 1.69 & .18 & -.29 \\
& Long-Term & 20 & 2.35 & 3.19 & 1.75 & 1.36 \\
\hline
\end{tabular}

As Table 1 shows, regarding the two groups' scores on short-term memory retrieval of target words, there

6 Consortia Academia Publishing (A partner of Network of Professional Researchers and Educators) 
Effect of doodling on Iranian EFL learners' foreign language classroom anxiety and lexical retrieval

was a mean difference of 1.70 points between the mean score in the experimental group $(M=5.54)$ and the mean score in the control group $(M=3.84)$. However, the mean difference for long-term memory retrieval of words between the experimental $(M=2.40)$ and control $(M=2.35)$ groups was small (.05). To investigate whether the short and long-term mean differences in the vocabulary retrieval were statistically significant, ANCOVA was conducted for each variable.

The key assumptions such as linearity between the dependent variable and the covariate for the ANCOVA were checked. The main ANCOVA results for the first research question, regarding doodling effect on the short-term memory retrieval of vocabulary, are displayed in Table 2.

\section{Table 2}

The results of ANCOVA for the short-term memory retrieval of words

\begin{tabular}{lcccccc}
\hline \multicolumn{1}{c}{ Source } & Sum of Squares & $d f$ & Mean Square & $F$ & Sig. & Partial Eta Squared \\
\hline Corrected model & $41.91^{\mathrm{a}}$ & 2 & 20.95 & 10.41 & .000 & .360 \\
Intercept & 31.43 & 1 & 31.43 & 15.61 & .000 & .297 \\
Pretest & 13.01 & 1 & 13.01 & 6.46 & .015 & .149 \\
Group & 20.94 & 1 & 20.94 & 10.40 & .003 & .220 \\
Error & 74.48 & 37 & 2.01 & & & \\
Total & 996.24 & 40 & & & & \\
Corrective total & 116.39 & 39 & & & & \\
\hline Note. a. R Squared $=.360$ (Adjusted R Squared $=.325)$. &
\end{tabular}

Note. a. $\mathrm{R}$ Squared $=.360$ (Adjusted R Squared $=.325$ ).

According to Table 2, there was a significant difference between the groups' post-instruction lexical gains, $F$ $(1,37)=10.4, * p<.05$, partial eta squared $=0.22$. It is noticeable that 22 percent of the variance in the dependent variable was explained by the instruction type.

\subsection{Long-term memory retrieval of words}

The same procedure was followed to investigate the doodling effect on long-term memory retrieval of the target words. The key assumptions such as linearity between the dependent variable and the covariate for the ANCOVA were checked. The main ANCOVA results for the second research question, regarding doodling effect on the long-term memory retrieval of vocabulary, are displayed in Table 3.

Table 3

The results of ANCOVA for the long-term memory retrieval of words

\begin{tabular}{lcccccc}
\hline \multicolumn{1}{c}{ Source } & Sum of Squares & $d f$ & Mean Square & $F$ & Sig. & Partial Eta Squared \\
\hline Corrected model & $41.10^{\mathrm{a}}$ & 2 & 20.55 & 2.48 & .097 & .118 \\
Intercept & 2.32 & 1 & 2.32 & .28 & .599 & .008 \\
Pretest & 41.10 & 1 & 41.10 & 4.96 & .032 & .118 \\
Group & 1.17 & 1 & 1.17 & .14 & .708 & .004 \\
Error & 306.27 & 37 & 8.27 & & & \\
Total & 573.00 & 40 & & & & \\
Corrective total & 347.37 & 39 & & & & \\
\hline Note. a. R Squared $=.118$ (Adjusted R Squared $=.071)$.
\end{tabular}

According to Table 3, there was not a significant difference between the groups' post-instruction lexical gains, $F(1,37)=0.142, p=.708$, partial eta squared $=.004$. In fact, doodling did not significantly affect the long-term memory retrieval of the lexical items.

\subsection{Doodling effect on foreign language anxiety}

The present research also examined the effect of doodling on the foreign language anxiety level experienced by the EFL learners. Table 4 shows the descriptive statistics for the foreign language anxiety in the experimental and control groups. 
Roohani, A., \& Naseri, F.

\section{Table 4}

Descriptive statistics for the foreign language anxiety in the experimental and control groups

\begin{tabular}{llccccc}
\hline \multicolumn{1}{c}{ Group } & \multicolumn{1}{c}{ Test } & $\mathrm{N}$ & $M$ & $S D$ & Skewness & Kurtosis \\
\hline Experimental & FLCAS (Pretest) & 20 & 66.45 & 14.17 & .32 & -.44 \\
& FLCAS (Posttest) & 20 & 61.65 & 14.30 & -.01 & -.03 \\
\hline Control & FLCAS (Pretest) & 20 & 62.60 & 16.41 & -.30 & -.17 \\
& FLCAS (Posttest) & 20 & 57.75 & 16.12 & .12 & .08 \\
\hline
\end{tabular}

As Table 4 shows, regarding the experimental group's scores on the FLCAS, there was a mean difference between the pretest $(M=66.45)$ and the posttest $(M=61.65)$. The mean scores on the FLCAS decreased from the pretest to the posttest. Similarly, the mean scores on the FLCAS in the control group decreased from the pretest $(M=62.60)$ to the posttest $(M=57.75)$. To investigate whether the mean differences on the foreign language anxiety were statistically significant, ANCOVA was conducted.

The main ANCOVA results for the third research question, regarding doodling effect on the foreign language anxiety, are displayed in Table 5. The posttest scores on the FLCAS were used as the dependent variable in the analysis.

\section{Table 5}

The results of ANCOVA for the foreign language anxiety

\begin{tabular}{lcccccc}
\hline \multicolumn{1}{c}{ Source } & Sum of Squares & $d f$ & Mean Square & $F$ & Sig. & Partial Eta Squared \\
\hline Corrected model & $3986.51^{\mathrm{a}}$ & 2 & 1993.25 & 14.78 & .000 & .444 \\
Intercept & 619.40 & 1 & 619.43 & 4.59 & .039 & .110 \\
Pretest & 3834.41 & 1 & 3834.41 & 28.43 & .000 & .435 \\
Group & 18.70 & 1 & 18.68 & .139 & .712 & .004 \\
Error & 4989.88 & 37 & 134.86 & & & \\
Total & 151540.00 & 40 & & & & \\
Corrective total & 8976.40 & 39 & & & & \\
\hline
\end{tabular}

Note. a. R Squared $=.444$ (Adjusted R Squared $=.414)$.

According to Table 5, there was not a significant difference between the groups' post-instruction foreign language anxiety levels, $F(1,37)=0.139, p=.712$, partial eta squared $=.004$. In fact, doodling did not significantly reduce the foreign language anxiety in the experimental group.

\section{Discussion}

Studies on the application of doodling as a relieving mechanism on language learning process are rare. Doodling has been envisaged as boosting the concentration and reducing the anxiety when mind starts daydreaming. However, its effect on L2 learners' foreign language classroom anxiety in the class and doodlers' short- and long-term memory retrieval of words has not been investigated. The aim of the present study was to investigate the effect of applying doodling activity/technique in the area of L2 vocabulary learning to investigate its potentials in boosting the short- and long-term memory retrieval of words as well as its effect on reducing the foreign language anxiety in the class. The results confirmed that lexical retrieval in short-term memory improved significantly. In other words, the EFL participants who used doodling strategy while listening inattentively could concentrate more on the lexical input and remembered a larger portion of lexical input. Short-term memory is said to keep input for a very limited period of time, and then the stored information tends to fade if not rehearsed (Repovs \& Baddeley, 2006). Doodling, in this view, triggers the short-term memory to store the input longer than the ordinary input storage. Also, Andrade's (2010) study demonstrated that information retrieval close to the time of storage was better accessed when doodling occurred.

This study was also intended at measuring the improvement of long-term memory retrieval of words triggered by doodling. Research on doodling has focused more on the immediate mental gains as a result of doodling; however, long-term memory is also important since much of the knowledge stored in the mind is used

8 Consortia Academia Publishing (A partner of Network of Professional Researchers and Educators) 
days after it is established. The above results of the study did not show any significant improvement in the participants' retrieval of the lexical information. The reason might be that doodling just functioned as a secondary solution only when instant mental capacities decreased, and its enduring effect notably faded, perhaps because the learners' input channel was limited and there was heavy mental traffic of lexical information. Also, research (e.g., Meade, Wammes, \& Fernandes, 2019) has showed that doodling, compared to note-taking strategy, has a very smaller role in subsequent retrieval of information. The other justification is that for input to be consolidated for later lexical retrieval, a minimum amount of attention seems to be necessary. Although doodling can compensate for the lack of the required attention, the attention span is short and memory cannot store all lexical information. In support of this justification, Baddeley (1986) points out that learners' low aural capacities, when they get bored, refute the chance for successful phonological codes' registration on the mental network and, consequently, fail in in adequate retentions. The learners' mind cannot have lexical information loading anymore, and doodling may not be useful in rendering this process so effectively. Though short-term retrieval of words improved for the doodlers, compared to nondoodlers, this effect could not last for a long time and both groups performed almost the same on the long-term memory vocabulary test. However, the role of some other confounding variables, such as intelligence and affective factors, cannot be ignored. They might have exerted some influence on the participants' long-term memory retrieval of words. This awaits further research in other contexts.

The last research question of the present study was concerned with the doodling effect on the L2 learners' foreign language anxiety when attentive learning would fade away. The analysis of the FLCAS data indicated that there was no significant difference between doodlers and non-doodlers in terms of their foreign language levels. Although previous research (e.g., de Guzman et al., 2008; Siagto-Wakat, 2016) showed doodling as a working strategy to unveil the internal feelings and attitudes towards an external subject, the present study did not substantiate the anxiety-reducing feature of doodling. The results of the current study revealed that doodling could not significantly reduce the foreign language anxiety learners experienced in the EFL class. It has been reported that foreign language classes, per se, are a cause of anxiety for L2 learners (Ohata, 2005; Masgoret \& Gardner, 2003). Anxiety increases when the time pressure and load of linguistic input increase in the classroom context. In such a context, doodling strategy cannot reduce foreign language anxiety in a significant way. Instead, it is better to use this strategy to examine the sources and types of anxiety experienced by learners in foreign language classes and find out a proper remedy for them.

\section{Conclusion}

Traditionally, doodling is assumed as a nonintellectual activity that prevents attention and is regarded as a sign of wasting time. However, in recent years, doodling has been considered as a strategy which meaningfully affects the retrieval of input in the mind (Andrade, 2010). The current study investigated the effect of doodling technique on EFL learners' retention of English words and levels of foreign language anxiety among a sample of Iranian EFL learners. When an EFL learner's mind loses its concentration due to the boredom, it gradually starts daydreaming and may create mental block for the learner as well as some management problems for the teacher. The results of the current study indicate that doodlers can improve short-term retrieval of target language vocabulary. However, doodling effects are restricted in terms of continuity, and doodling activity cannot be regarded as a primary technique to boost EFL learners' long-term memory retrieval of English words. Rather, it can be utilized as a temporary and compensatory mechanism when boredom obscures mental operations. By implications, in normal conditions where L2 learners deal with linguistic elements attentively, other strategies might be more effective to maximize the retrieval of word meanings in the long-term memory. The above findings imply that doodling can serve as an attention-attractor in order to assist L2 teachers in class management by managing L2 learners' boredom and stress level momentarily, and providing more memory space for L2 vocabulary pick up. However, doodling activity cannot have long-run effects on lexical retrieval of target language vocabulary. Furthermore, the results on the effect of doodling on the EFL participants' foreign language anxiety indicate that doodlers may not feel significantly less anxious than non-doodlers in the EFL 
classroom, in general. Perhaps, doodling can function well as a strategy to help L2 teachers to surface just the covert causes of anxiety in their individual learners and find some ways to help some learners overcome their anxiety. Based on the results, doodling might not be very effective for the whole class as an anxiety-reduction strategy in L2 lexical learning. Rather, as MacKillop and Anderson (2007) suggest, it can provide some learners with a metacognitive tool to self-regulate their own stress and improve their short-term performance in a learning context.

\section{References}

Allwright, D., \& Bailey, K. M. (1991). Focus on the language classroom: An introduction to classroom research for language teachers. Cambridge: Cambridge University Press.

Andrade, J. (2010). What does doodling do? Applied Cognitive Psychology, 24(1), 100-106. https://doi.org/10.1002/acp.1561

Awan, R., Azher, M., Anwar, M. N., \& Naz, A. (2010). An investigation of foreign language classroom anxiety and its relationship with students' achievement. Journal of College Teaching and Learning, 7(11), 33-40. https://doi.org/10.19030/tlc.v7i11.249

Baddeley, A. (1986). Working memory. Oxford: Oxford University Press.

Benjamin, L. T. Jr. (2002). Lecturing. In S. F. Davis \& W. Buskist (Eds.), The teaching of psychology: Essays in honor of Wilbert J. McKeachie and Charles L. Brewer (pp. 57-67). Mahwah, NJ: Lawrence Erlbaum Associates, Inc.

Bila, M. (2005). The phonic perception of reduced input by nonnative speakers in comparison with native speakers and immigrants. Presov: FHPV.

Boggs, J. B., Cohen, J. L., \& Marchand, G. C. (2017). The Effects of doodling on recall ability. Psychological Thought, 10(1), 206-216. https://doi.org/10.5964/psyct.v10i1.217

Brown, S. (2011). Doodlers unite [video]. TED Conference in New York. Retrieved from https://www.ted.com/talks/sunni_brown.html

Chan, E. (2012). The negative effect of doodling on visual recall task performance. University of British Columbia's Undergraduate Journal of Psychology, 1, 1-6.

de Guzman, A., Pablo, L. A., Prieto, R. J., Purificacion, V. N., Que, J, J., \& Quia, P. (2008). Understanding the persona of clinical instructors: The use of students' doodles in nursing research. Nurse Education Today, 28(1), 48-54. https://doi.org/10.1016/j.nedt.2007.02.012

Doherty, M. S. (2005). Serious doodles. American Artist, 69(754), 28-31.

Dörnyei, Z. (1994). Motivation and motivating in the foreign language classroom. Modern Language Journal, 78, 273-284. https://doi.org/10.1111/j.1540-4781.1994.tb02042.x

Dörnyei, Z. (2001). Teaching and researching motivation. Edinburgh Gate, England Pearson Education.

Dukette, D., \& Cornish, D. (2009). The essential 20: Twenty components of an excellent health care team. Rose Dog Books.

Goss-Lucas, S., \& Bernstein, D. A. (2005). Teaching psychology: A step by step guide. Mahwah, NJ: Lawrence Erlbaum Associates, Inc.

Grillon, C. (2008). Models and mechanisms of anxiety: Evidence from startle studies. Psychopharmacology, 199, 421-437. https://doi.org/10.1007/s00213-007-1019-1

Gupta, S. (2016). Doodling: The artistry of the roving metaphysical mind. Journal of Mental Health and Human Behavior, 21(1), 16-19. https://doi.org/10.4103/0971-8990.182097

Horwitz, E. K., Horwitz, M. B., \& Cope, J. (1986). Foreign language classroom anxiety. Modern Language Journal, 70(2), 125-132. https://doi.org/10.1111/j.1540-4781.1986.tb05256.x

Kleinmann, H. H. (1977). Avoidance behavior in adult second-language acquisition. Language Learning, 27, 93-107. https://doi.org/10.1111/j.1467-1770.1977.tb00294.x

Leal, P. C., Goes, T. C., da Silva, L. C., \& Teixeira-Silva, F. (2017). Trait vs. state anxiety in different threatening situations. Trends Psychiatry Psychotherapy, 39(3), 147-157.

https://doi.org/10.1590/2237-6089-2016-0044

10 Consortia Academia Publishing (A partner of Network of Professional Researchers and Educators) 
Effect of doodling on Iranian EFL learners' foreign language classroom anxiety and lexical retrieval

Lewis, M. (1993). The lexical approach. Hove, England: LTP.

Lim, H. Y. (2004). Effects of task values, attributions, and cultural constructs on foreign language use anxiety among international teaching assistants [Doctoral dissertation]. Texas University.

MacIntyre, P. D. (2002). Motivation, anxiety, and emotion in second language acquisition. In P. Robinson (Ed.), Individual differences in second language acquisition (pp. 45-68). Amsterdam: John Benjamins. https://doi.org/10.1075/1llt.2.05mac

MacIntyre, P. D., \& Gardner, R. C. (1989). Anxiety and second language learning: Toward a theoretical clarification. Language Learning, 39, 251-275. https://doi.org/10.1111/j.1467-1770.1989.tb00423.x

MacKillop, J., \& Anderson, E. J. (2007). Further psychometric validation of the mindful attention awareness scale (MAAS). Journal of Psychopathology and Behavioral Assessment, 29, 289-293. https://doi.org/10.1007/s10862-007-9045-1

Masgoret, A. M., \& Gardner, R. C. (2003). Attitudes, motivation, and second language learning: A meta-analysis of studies conducted by Gardner and associates. Language learning, 53(1), 123-163. https://doi.org/10.1111/1467-9922.00212

Meade, M. E., Wammes, J. D., \& Fernandes, M. A. (2019). Comparing the influence of doodling, drawing, and writing at encoding on memory. Canadian Journal of Experimental Psychology, 73(1), 28-36. https://doi.org/10.1037/cep0000170

Ohata, K. (2005). Potential sources of anxiety for Japanese learners of English: Preliminary case interviews with five Japanese college students in the U.S. TESL-EJ, 9(3), 1-21.

Randler, C., Wüst-Ackermann, P., Vollmer, C., \& Hummel, E. (2012). The relationship between disgust, state-anxiety, and motivation during a dissection task. Learning and Individual Differences, 22, 419-424. https://doi.org/10.1016/j.lindif.2012.01.005

Repovs, G., \& Baddeley, A. D. (2006). The multi-component model of working memory: Explorations in experimental cognitive psychology. Neuroscience, 139(1), 5-21. https://doi.org/10.1016/j.neuroscience.2005.12.061

Romani, C., \& Martin, R. C. (1999). A deficit in the short-term retention of lexical-semantic information: Forgetting words but remembering a story. Journal of Experimental Psychology: General, 128, 56-77. https://doi.org/10.1037/0096-3445.128.1.56

Scovel, T. (1978). The effect of affect on foreign language learning: A review of anxiety. The Modern Language Journal, 76(1), 14-26. https://doi.org/10.1111/j.1467-1770.1978.tb00309.x

Siagto-Wakat, G. (2016). Doodling the nerves: Surfacing language anxiety experiences in an English language classroom. RELC Journal, 48(2), 226-240. https://doi.org/10.1177/0033688216649085

Singh, T., \& Kashyap, N. (2015). Does doodling effect performance: Comparison across retrieval strategies. Psychological Studies, 60, 7-11. https://doi.org/10.1007/s12646-014-0293-3

Smallwood, J. S., \& Schooler, J. W. (2006). The restless mind. Psychological Bulletin, 132(6), 946-958. https://doi.org/10.1037/0033-2909.132.6.946

Sparks, R. L., \& Ganschow, L. (1991). Foreign language learning differences: Affective or native language aptitude differences? Modern Language Journal, 75, 3-16. https://doi.org/10.1111/j.1540-4781.1991.tb01076.x

Sparks, R. L., Ganschow, L., \& Javorsky, J. (2000). Deja vu all over again: A response to Saito, Horwitz, and Garza. The Modern Language Journal, 84(2), 251-255. https://doi.org/10.1111/0026-7902.00066

Stroud, C., \& Wee, L. (2006). Anxiety and identity in the language classroom. RELC Journal, 37, 299-307. https://doi.org/10.1177/0033688206071311

Tremblay, P. F., \& Gardner, R. C. (1995). Expanding the motivation construct in language learning. Modern Language Journal, 79, 505-520. https://doi.org/10.1111/j.1540-4781.1995.tb05451.x

Tsui, A. B. M. (1996). Reticence and anxiety in second language learning. In K. M. Baily \& D. Nunan (Eds.), Voices from the classroom (pp. 145-167). Cambridge: Cambridge University Press.

Young, D. J. (1990). An investigation of students' perspectives on anxiety and speaking. Foreign Language Annals, 23, 539-553. https://doi.org/10.1111/j.1944-9720.1990.tb00424.x 
Roohani, A., \& Naseri, F.

12 Consortia Academia Publishing (A partner of Network of Professional Researchers and Educators) 